Research Article

\title{
Metaheuristic and Machine Learning-Based Smart Engine for Renting and Sharing of Agriculture Equipment
}

\author{
Manik Rakhra $\mathbb{D}^{1},{ }^{1}$ Ramandeep Singh $\mathbb{D}^{1},{ }^{1}$ Tarun Kumar Lohani $\mathbb{D}^{2}$ \\ and Mohammad Shabaz $\mathbb{D}^{1}$ \\ ${ }^{1}$ Department of Computer Science and Engineering, Lovely Professional University, Phagwara, Punjab 14411, India \\ ${ }^{2}$ Arba Minch University, Arba Minch, Ethiopia \\ Correspondence should be addressed to Ramandeep Singh; ramandeep.singh@lpu.co.in
}

Received 21 January 2021; Revised 3 February 2021; Accepted 11 February 2021; Published 28 February 2021

Academic Editor: Dilbag Singh

Copyright ( 92021 Manik Rakhra et al. This is an open access article distributed under the Creative Commons Attribution License, which permits unrestricted use, distribution, and reproduction in any medium, provided the original work is properly cited.

Recently, many companies have substituted human labor with robotics. Some farmers are sharing different perspectives on the incorporation of technology into farming techniques. Some are willing to accept the technology, some are hesitant and bemused to adapt modern technology, and others are uncertain and are worried about the potential of technology to cause havoc and decrease yields. The third group prevails the most in the developed world, for lack of know-how, including translation of utility and, most significantly, the expense involved. A special Smart Tillage platform is established to solve the above issues. A smart-engine-based decision has been developed, which further uses classification and regression trees to shift towards decision-making. The decision is focused entirely on different input factors, such as type of crop, time/month of harvest, type of plant required for the crop, type of harvest, and authorised rental budget. Sitting on top of this would be a recommendation engine that is powered by deep learning network to suggest the escalation of a farmer from lower to higher category, namely, small to medium to large. A metaheuristic is one of the best computing techniques that help for solving a problem without the exhaustive application of a procedure. Recommendations will be cost-effective and suitable for an escalating update depending on the use of sufficient amends, practices, and services. We carried out a study of 562 agriculturists. Owing to the failure to buy modern equipment, growers are flooded by debt. We question if customers will be able to rent and exchange appliances. The farmers would be able to use e-marketplace to develop their activities.

\section{Introduction}

India is a nation mainly connected with agriculture, where real achievement in agriculture was achieved through the use of agriculture machinery. Mechanization of agriculture involves the use of various tools and equipment, which helps to conduct farming activities expediently and skillfully. This will relieve the farmers from the burden of the physical work. By 2050, we need to feed more than 10 billion people, which would entail $70 \%$ increase of global food production [1-3]. There are 1.3 billion farmers in the world, many of whom already lack access to equipment and new technologies. In various developing countries, although they have excess land, because of little land ownership and credit constraints, farmers cannot use capital to improve their production and livelihoods. In India, land under farm mechanization is less than $30 \%$. This is because $75 \%$ of farmers have less than 1 hectare of land $[4,5]$. This small land ownership prohibits families from getting agricultural equipment solely for their own purposes. Farmers lease machinery from people who lend their equipment monetarily. Farmers face numerous problems with the renting of farming equipment, such as limited access for borrowers, no appointments, high prices, and untrustworthy transport. These difficulties result in reduction of the farmers' yields. Various tractor and combine pieces of equipment are usually very expensive for small and medium category of farmers [6]. They must therefore obtain rental services from some other owners of machinery who often lease them high rent in the peak season. There is also lack of certainty about the machinery's availability during use. Over half of the farmers in India have less than 4 acres of land [7]. Although farmers equipment is not priced 
at very high rates, still farmers are unable to buy the farming tools. Most mechanization approaches of agricultural practices have concentrated more on providing tractors but do not focus on other resources that are as relevant as using tractors [8]. The explanation for this could be because they are not informed of modern tools and equipment on the market. The Internet of Things plays a wonderful function all over the world. The term "Internet of Things (IOT)" was first assessed by British visionaries in 1999. IOT supplies the knowledge of the technical world. Agriculture is a significant field that is heavily affected by IOT. At a higher stage, the knowledge obtained from several heterogeneous sources can be arranged in the form of smart algorithms to include creative information in the ongoing process. This allows controlling the data transmitted in real time to run through the node of the Wireless Sensor Network (WSN). Figure 1 demonstrates the rise in the term IOT along with agriculture. IOT aims to pull together knowledge such as data collection from smart agricultural devices, tracking internal operations and reducing output hazards, eliminating waste and controlling costs, improving market efficiency, and maximizing productivity. The key aim of this paper is to share the forum for smart agriculture problems.

Custom hiring is an emerging pattern for agriculture, which encourages improved use of financial capital in the farm staff, thus building a sensible plan for agriculture. $\mathrm{CHCs}$ are essentially commodities that are bundles of field machinery, farm equipment, and farming products for growers. In order to get advantages of advanced technologies and robotics, citizens have to take a move in the face of automation farming. Certain businesses take this step in provision of agricultural machinery for lease as well as for custom hiring [9]. Such assets-sharing systems are in hot demand with respect to farm machinery and equipment in some regions at a lower cost for farm workers. While studying history of tractor cultivation in selected areas, the average use of the tractor was 739 hours a year or almost two hours per day. Average hiring hours per tractor were worked out at 76 hours annually, and $61 \%$ of the total hired tractor hours represented an assessed trend of economic activity in state developed agricultural sector [10-12]. In a nutshell, farmers can operate farmlands with customized hiring of tools. Farmers with land below 2.8 acres are potential users of farming equipment through customized rental agencies [13].

Figure 2 depicts the concept for the custom hiring. Custom hiring by farmers needs neither startup nor repair and maintenance expenses. They just charged custom service costs and chargeable services. Theoretical ideas have been developed, taking into account the ultimate objective of choosing the ideal task of hardware and assets to reduce farming costs and accessibility. The proposed result will be helpful for the farmers to complete their agricultural task on time. This would keep away the loss of production due to delays in agricultural activities. In 2000, experts created a decision support model that offers the optimal equipment and task variation to reduce expenses $[14,15]$. The decisionmaking system performs a credit check of agricultural equipment duties on different crop records, field work, schedules of operations, and so forth. The framework suggests choices for the purchasing or lease of resources and how they would be deployed. Motivated by all of this, they evaluated that the normal total tractor running costs by a shot attempt increased to 577.70 rupees per hour, while costs of social orders were 38 percent lower than the total cost of tractors per hour [16]. More experiments have been conducted on development measure and financial efficiency. The analysis demonstrates that large farmers benefited far more in economic output than medium- and small-scale farmers who increased by $43.04 \%$ and $17.02 \%$ [17-19]. This was a direct consequence of the fact that large farmers have better technology, but small farmers cannot afford it. There is also a tremendous extension for small farmers to configure the equipment. Every year, 90 percent of the farmers purchasing tractors spent less than 400 hours, more of which they spent on transport and the loading or clearing of stuff. A metaheuristic is one of the better computing methods to address an issue without the thorough usage of a method. Metaheuristic is one of the promising strategies to find optimal outcomes for equipment rental and sharing. Smart Tillage is mainly concerned in agriculture with the enhancement of agriculture's quality and productivity. Mechanization would also help to generate friendly social orders, farmers' clubs, customer care channels, and agricultural leasing machinery that will render such administrations cheaper at the level of agriculture.

Many experiments are aimed at determining repair and service costs for equipment with a particular end purpose, as it has been reported that repair and maintenance costs have reduced by 1,000 hours per year. Experts have calculated the impact of the period of the tractor, the annual utilization, the development and modeling, and the estimation of the maintenance and service costs of agricultural machinery per hour. It was reported that, with annual usage, maintenance and repair costs have risen. The repair and operation costs were directly related to age and, conversely, to the daily usage of the tractor. Instead of owning farm machinery, a large number of people voted in favor of custom hiring, particularly for small farmers, because of the high risk.

Metaheuristic method is one that need not particularly have a mathematical proof and looks for an approximate solution; each and every solution does not explore. For example, the primitive method of randomly picking solution for a certain number of iterations completely represents explorative research. For every iteration, multiple solutions get modified. Modification of solution is done through apparatus often using special statistical properties in such a way where metaheuristic techniques are used to modify the solution through various operators/parameters which can be further helpful to find the optimized results that will be beneficial for renting and sharing of equipment.

\section{Concept of Agricultural Mechanization}

Agriculture mechanization is the building block of renting and sharing of equipment. It enhances productivity by automated tools resulting in reducing human effort and cost of cultivation. Agricultural mechanization has been defined 
in a number of ways. It refers to the use of machines, equipment, and driven machinery in agricultural inputs to achieve agricultural output and increase land productivity [20-22]. Agricultural mechanization has three primary renewable technologies: human power, drawn chemical fertilizers, and mechanical work.

Human power is the early and most fundamental stage of farm mechanization, since manpower is used for manufacturing hand tools and simple tools [23, 24]. Draught animal energy uses animal core strength in machinery and operating tools to carry out farming tasks [2]. The higher level of development in the mechanization of agriculture is mechanical strength, in which the use of farm equipment is from other sources rather than physical force $[25,26]$. Many of the examples other than physical forms of agricultural energy available for a variety of farming activities include wind power, solar energy, water power, and electricity and combustion engines [25]. Use of such sources differs from country to country and depends on local conditions [27], specifically the availability of forms of energy [28].

The sector of agriculture automation is very wide, covering the use of farm machinery and its use techniques [29-33]. Sustainable agriculture covers effective and efficient delivery of mechanization inputs to farmers, which involves the manufacture or import, distribution of farm equipment, installation and maintenance (including replacement parts) facilities, governmental support, and use of farming tools and equipment. Meanwhile, the use of mechanisms in farm development operations involves farmers' growth of field and crop production, harvesting, preservation, and on-farm processing [30].

In this recent research, the primary focus is to sensitize the farmers for agriculture mechanization. The main aim of this work is to make awareness among the farmers about the smart tools and equipment and to promote renting and sharing. This renting and sharing will further assist the farmers to get the required equipment at the peak time. For this, we have developed a decision support system that covers the numerous benefits for the farmers. With this framework, farmers will get the right equipment at the right time. It will increase profitability and farm productivity [34-38]. Figure 3 depicts the snapshot of the created framework. This will help the farmers to get relief from the burden of loan which they take unnecessarily for buying equipment. This system will further resolve the problem of shortage of labor and improve the social status of the farmers in rural areas $[39,40]$. With this system, farmers will get aware of upcoming government policies. The proposed system will provide job to many youth farmers. In this applied research, we have conducted a survey at the social and economic level, for the acceptance and usage of a technological solution to promote farm equipment sharing and renting. After the survey, we have developed the framework that can accommodate the farm equipment sharing and renting considering seasonal fluctuations, market demand, and pricing as per the crop cycles. For smart assistance of farmers, we have also designed and developed an Internet-based mobile application for the various types of end-users, which can be used to advertise, reserve, rent, and share agricultural equipment.

\section{Materials and Methods}

This chapter includes the results and discussion of Internetbased Smart Agriculture Resource Sharing Framework. Herein, the data collection of 562 farmers has been done and after that this collected data was analyzed. For the valuable analysis of data, a smart algorithm system is used, which can be further used for the technological solution to promote farm equipment renting and sharing. The collected samples were analyzed by machine learning network like a fuzzy neural network or neurofuzzy system which finds the parameters of a fuzzy system. On the basis of these collected data, an Internet-based mobile application is launched, which can be used to advertise, reserve, rent, and share agricultural equipment.

The proposed work is carried out for the improvement in the field of agriculture. The rate of agriculture productivity is falling very vastly. Fluctuation in the farming is based on the number of parameters that are mainly responsible for the farmers, including educational qualification, age, annual income, expenditure, number of family members, lack of technical knowledge, being under the burden of loans, tools they have, the reason for loans, and many more [30]. These above-mentioned problems are responsible for the downfall of farming in Punjab. In order to consider this, a socioeconomic level survey has been conducted and the usage of a technological solution has been done to promote renting and sharing of farm equipment. An Internet-based mobile application for the various types of end-users which can be used to advertise, reserve, rent, and share agriculture equipment is designed, developed, and launched. Analysis of these collected data has been illustrated by different parameters.

In order to analyze the data, the farmers are divided into three categories, that is, small, medium, and large. From the total 562 farmers, 377 farmers fall under the category of small farmers, 179 lie in the category of medium farmers, and 6 farmers fall in the category of large farmers. The main issue of the farmers is that they are not sensitized with the modern equipment and tools and on the flip side they are falling under the burden of debt which forces them to commit suicide. In order to resolve this concern of the farmers, we have developed an Uberized model named Smart Tillage, which deals with the renting and sharing of farming equipment. So, in order to run this Uberized model, our first concern is to find how many farmers have their own smartphones. Figure 4 represents the results of the collected information: in the small farmers' category, out of 377 farmers, 155 farmers have their smartphones; in the medium farmers' category, out of 179 farmers, 144 farmers have their smartphones; and, in the large farmers' category, out of 6 farmers, 5 farmers have their smartphones.

Out of these, all the farmers in the small farmers' category, that is, 377, 178 farmers in the medium farmers' category, and 1 farmer in the large farmers' category are interested in smartphones as shown in Table 1. The concept 
of this parameter selection is reached to the view of custom hiring system so that farmers can rent and hire their equipment accordingly.

3.1. Basic Information. The basic information regarding farmers' category interested in mobile app and smart phones is given Table 1 .

\subsection{Farmers' Category with Expenses and Their Income.} Figure 5 depicts the comparison of farmers in small, medium, and large categories on the basis of their expenses, count, income from agriculture, and count of farmers. Table 2 represents that all the farmers in the different categories had their per month expenses in the ranges of $10,000-25,000,25,000-50,000$, and more than 50,000. These expenses are labeled as $\mathrm{A}, \mathrm{B}$, and $\mathrm{C}$ under the three different categories: small, medium, and large. For label A, 146 farmers fall under the small category, 56 under the medium category, and 3 under the large category. For label B, 225 farmers fall under the small category, 120 under the medium category, and 3 under the large category. Similarly, for label C, 6 farmers fall under the small category, 3 fall under the medium category, and no farmers under the large category. However, the next part of this table represents farmers' categories with income from agriculture and their number of counts. In order to consider this, income from agriculture is categorized into three groups, that is, 50,000-2,00,000, $2,00,000-5,00,000$, and more than 5,00,000. This income from agriculture is labeled as D, E, and F. For label D, 377, 19 , and 1 farmers fall under the small, medium, and large categories, respectively. For label E, 1, 159, and no farmers fall under the small, medium, and large categories, categories. For label F, 0, 1, and 5 farmers fall under the small, medium, and large categories, respectively.

\subsection{Analysis between Farmers' Category, Reason for Loan, and} Their Wish to Hire Machinery. Table 3 depicts based on the three categories of the farmers: small, medium, and large. Out of all categories, some of the farmers are interested in loan, while others are not. Loan is one of the main causes that force the farmers to commit suicide. From this mentioned analysis, this inference depicts that the maximum farmers from different categories have taken loan to buy new machinery. This survey reached the result that farmers are under the burden of loans due to the following reasons:

\section{(i) Plantation and fertilization \\ (ii) New machinery \\ (iii) Land development \\ (iv) Education}

Figure 6 represents that, out of 377 small farmers, 179 are interested in loan and 198 are not interested in loan, and all the 179 who are interested in loan are interested in hiring machinery. In the medium category, out of 179 farmers, 53 have loans, while the others are not involved in loans. The remaining 124 farmers are interested in hiring machinery. There are 5 farmers from the large farmer group who are interested in loan and 2 farmers who are not interested in loan but they are interested in hiring machinery. Figure 5 also depicts the reason for loan for the farmers. This analysis reached the mark that this is the reason due to which farmers think of committing suicide.

3.4. Analysis of Distance up to Which Different Categories of Farmers Are Willing to Share Their Tools/Equipment. To link with the above-mentioned analysis, the next parameter focused on for how much distance farmers are willing to share their tools. This sharing of tools will be further helpful for those farmers who are unable to buy farming equipment. In this recent research, our main focus was on the renting and sharing of farming equipment so in order to view this developed questionnaire includes this question too, that is, considerable distance while landing machinery. This table describes different categories of the farmers with different attributes such as they do not have any tool or they can share their tools up to $3 \mathrm{~km}, 5 \mathrm{~km}, 10 \mathrm{~km}$, and more than $10 \mathrm{~km}$. From this conducted survey in different district with various villages, we analyzed that the farmers are willing to share and rent the equipment. This analysis describes the farmers category: small, medium, and large. Table 4 shows how many farmers are willing to rent and share equipment and for how much distance. Figure 7 also describes the count of farmers for sharing of their tools.

3.5. Analysis between Different Categories of Farmers and Different Types of Crops versus Difficulty in Finding Machinery and Taking Loan for It. To find the difficulty in hiring machinery, our main focus is to investigate what sort of hurdles farmers face when locating the equipment. Sharing of tools along with these gaps is further based on the community of the farmers, kind of crops, and their difficulties to find equipment and their cause of taking the loan. This analysis describes traditional and modern kinds of farming, which further relate to the category of the farmers: small, medium, and large. Table 5 represents different kinds of crops that the farmers have with traditional and modern techniques. Figure 8 also describes the farmers' interest in hiring machinery and taking loans. This analysis reaches the result that most of the farmers in the small category have found difficulty in hiring machinery and, due to this reason, they fall under the burden of loan; because of these issues, they commit suicide.

\section{Smart Tillage}

In this research methodology, we have developed a recommendation engine Smart Tillage for smart, quick, and efficient sharing and renting of farming equipment using smart decision rule engines and/or classification and regression trees. The aim of this framework, Smart Tillage, is a smart application which will aid a low-income farmer, who does not own a lot of farming equipment, to find and connect with another well-to-do farmer who owns farming 


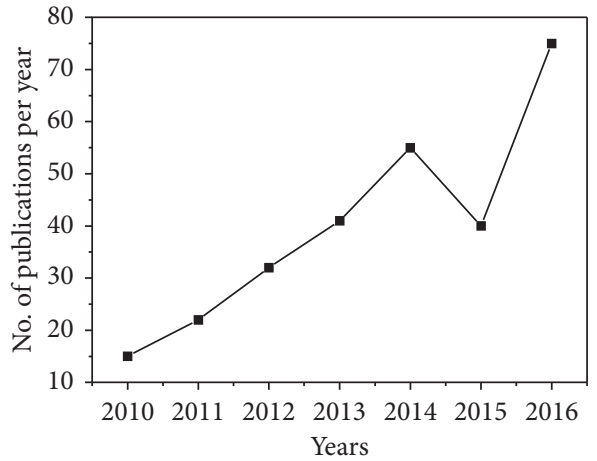

FIGURE 1: Number of publications related to "IOT in agriculture."

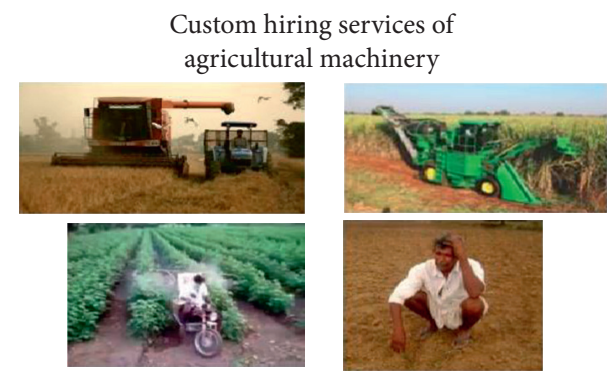

FIGURE 2: Concept for the custom hiring.

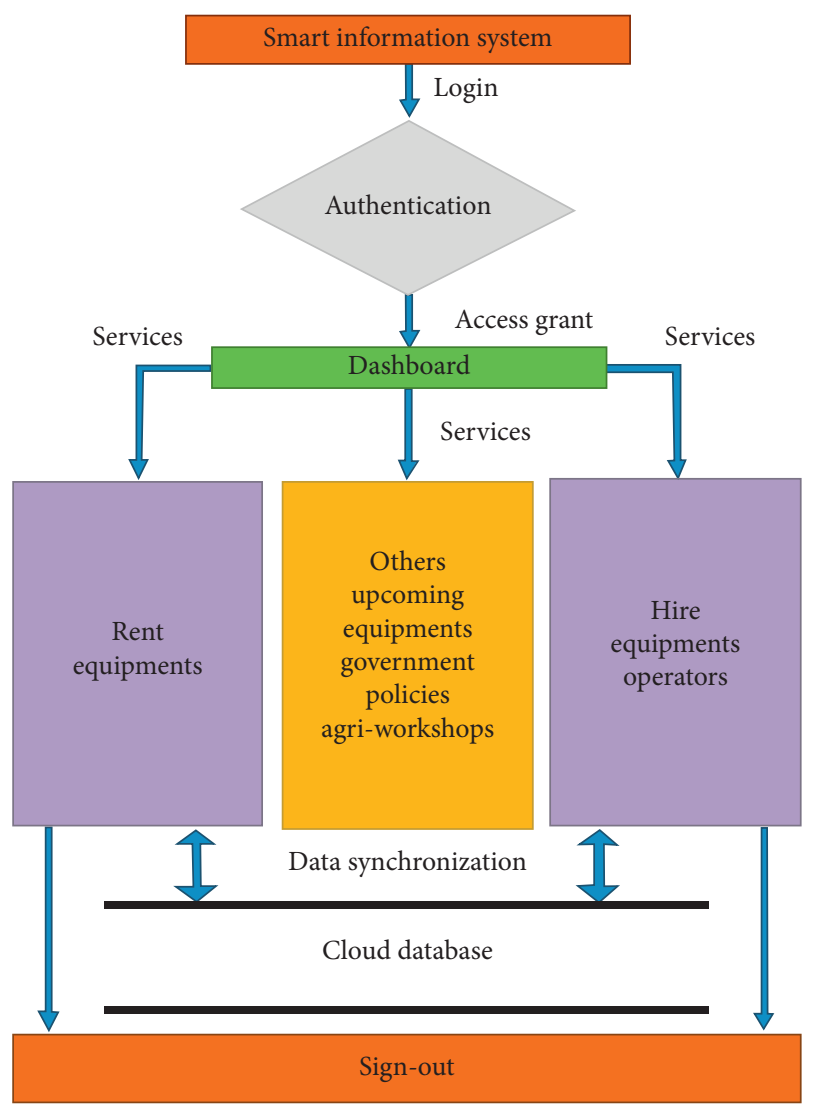

Figure 3: Layout of the developed structure. equipment of his own for rental and sharing purposes. In this smart application, we have embedded a basic-rules engine at the core of the application, which consists of various rules embedded into the system. When a farmer is registered into the system and decides to avail the services, the smart engine provides recommendations to the farmer as regards which kind of equipment is necessary for his upcoming farm work.

4.1. System Architecture. In this smart farming system, the authors employed a dispatch optimization to allocate the resources and equipment required for planting by farmers. In this, farmers engage with each other with real-time applications so that they can pump up the citizens marketing. For logging, we use several KAFKA clusters, and the data is processed into Hadoop. Figure 9 reflects the design of dispatch optimization with the renting and sharing. In this architecture, the requests are handled on the server side. Every request is sent to the Web application firewall (WAF) followed by load balancing. After every 4 seconds, the supply module will keep on updating the location data to the KAFKA rest API. The request goes to KAFKA rest API and it will keep updating the location by passing it through KAFKA and a copy is sent in the database and also to dispatch optimization to keep the latest location of the equipment and tools. WAF is used for the security purpose. To block the request from blocked IP, we have used a load balancing on application-level layer in this framework. KAFKA rest API will provide the end point to consume all the location data for the equipment. For instance, we have 400 farmers who are sharing their equipment in a city which means for every user we have 400 hits and 400 location points that are being sent to the KAFKA. The data will be processed by the KAFKA followed by different components. A copy of all the requests will be saved in NOSQL where the equipment is shared and latest location will be sent to DISCO (dispatch optimization) which will make the framework updated.

For sending a message from a farmer to the server and from the server to a farmer, we need a synchronous way for which we use web socket. For changes that happen in the dispatch system on any component in the server, the data will be exchanged to and from the application. So web socket is written in NodeJS as NodeJS is really good in sending synchronous message and also it is an event-driven framework. In dispatch optimization, the server can push the data and send the data to the application whenever it wants as NodeJS is used. To distribute the work between the servers in this framework, REPO is used. It does consistent hashing to distribute the equipment among the farmers. Process of remote desktop connection calls is used to make request from one server to another server.

A "Gossip protocol" is used to add new server in the ring and also to ensure that the data is provided to the entire servers in the ring. In the real time when the farmer will request equipment, this request will land to the web socket and will pass the request to the demand/supply dispatch optimization which will handle all the requests of all the 

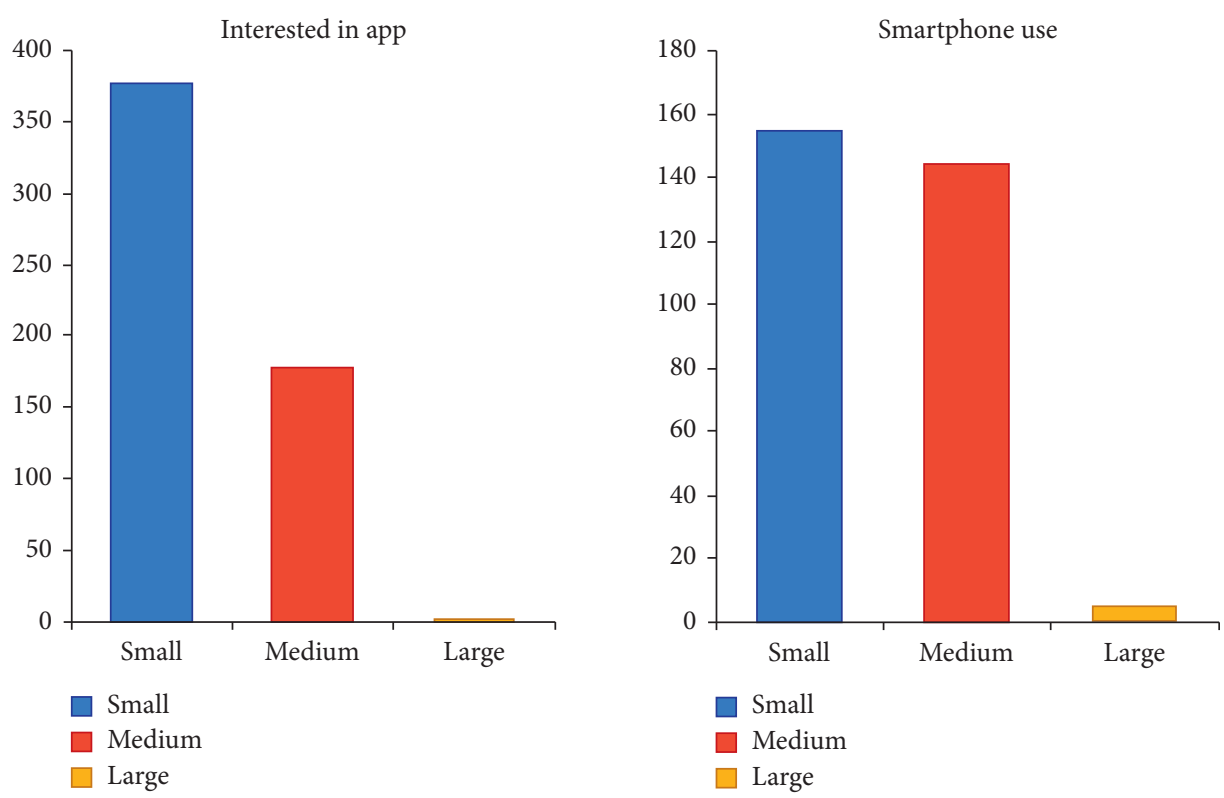

Figure 4: Analysis of farmers category versus interest in mobile app.

TABLE 1: Farmers' category interested in mobile app and smartphones.

\begin{tabular}{lccc}
\hline \multicolumn{2}{c}{$\begin{array}{c}\text { Analysis of farmer category versus interest in app. } \\
\text { Farmers category }\end{array}$} & \multicolumn{2}{c}{ Analysis of farmer category versus smartphone use } \\
Interested in app. & Farmer category & Smartphone use \\
\hline Small & 377 & Small & 155 \\
Medium & 178 & Medium & 144 \\
Large & 1 & Large & 5 \\
\hline
\end{tabular}

tools and equipment. Since the demand service is updated with the location and the demand of the farmers and will request the supply that the farmers need the equipment in this particular location by providing the request ID, now the request from the supply will go to all the servers in the circle; for example, the supply service using web sockets will sense the request and provide the information to the farmers of the equipment that are very near to the user. So once the user accepts the offer the equipment will be provided to the user. The request is passed to all the servers by remote desktop connection. All the servers respond back to the supply server and after mapping the demands send the result to the user. Google Astrolibrary is used to break the maps into different cells that are used to easily locate the equipment to the farmers.

4.2. Rule-Based Model for Renting and Sharing. In this applied research, we have made a decision support system named Smart Tillage. Smart Tillage will help the farmers to rent and share equipment. Figure 10 depicts the outlook of the smart application. Renting and sharing tools is just a kind of string having two ends: one represents the user who wants to share their modern agriculture equipment/tools and the other is a farmer who needs the equipment. To promote renting and sharing, we have created a framework in which the user will login. Thinking of this uncertainty that the farmers are not much updated with the technology, we have made a signup just by entering the phone number and password. The location will be automatically fetched by entering the pin code.

Herein, a decision based smart engine has been created, which further uses classification and regression trees to climb towards a decision. The decision is based entirely on various input parameters like the kind of crop, time/month of harvest, kind of equipment needed for the crop, type of harvest, approved budget for renting, and so forth. For every registered farmer, the above parameters and more are collected in a readable format which is embedded into the rule engine. The rule engine sorts through the various rules embedded in the system and provides one optimal and a few suboptimal alternate recommendations to the farmer. The recommendation will generally be in the form of different farmer contact details, some or all of whom are willing to rent out the equipment during that time of the year and have the equipment available (not prebooked) for rentals.

The embedded rule engine is situated at the core of Smart Tillage and is the heart of the entire application. The rule engine takes into account all the various parameters provided by the requesting farmer like harvesting crop, time/ month of harvest, approved budget, distance factor, kind of equipment, and so forth, and scours through the rule engine to find the appropriate owner of the above-mentioned equipment. If the rule engine is embedded with specific 

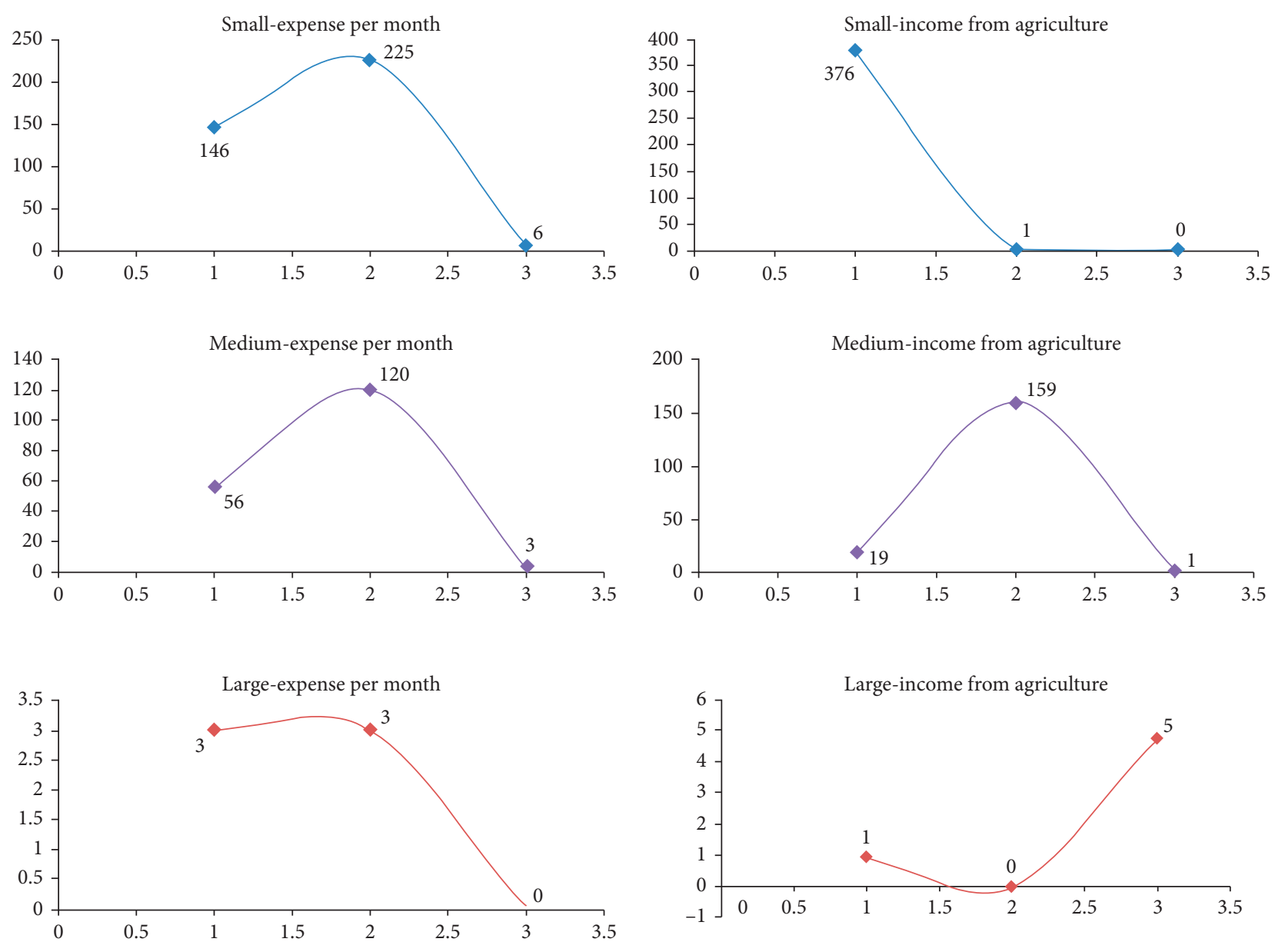

FIGURE 5: Farmers' category versus expenses per month and income from agriculture.

TABLE 2: Farmers' category with monthly expenses and income from agriculture.

\begin{tabular}{lcccc}
\hline Farmers category & Per month expense & Count of farmers & Income from agriculture & Count of farmers \\
\hline \multirow{3}{*}{ Small } & $10000-25000$ & 146 & $50000-200000$ & 376 \\
& $25000-50000$ & 225 & $200000-500000$ & 1 \\
& More than 50000 & 6 & More than 500000 & 0 \\
Medium & $10000-25000$ & 56 & $50000-200000$ & 19 \\
& $25000-50000$ & 120 & $200000-500000$ & 159 \\
\hline \multirow{3}{*}{ Large } & More than 50000 & 3 & More than 500000 & 1 \\
& $10000-25000$ & 3 & $50000-200000$ & 1 \\
& $25000-50000$ & 3 & $200000-500000$ & 5 \\
\hline
\end{tabular}

rules, it comes up with better solutions. The rule engine also provided optimal results if the numbers of rules keep increasing, provided the rules do not clash with each other.

A basic binary tree is used to model the decision tree. Each node represents an input variable/parameter along with a decision factor at its core. The decision factor is basically if/else clause which makes a decision using the rules from the rule engine. The path to be taken from the node would depend on the output from the rule engine. In this way, the final decision taken would be obtained by cruising through the tree nodes and taking optimal paths at each node until we reach the end of the tree which would be the leaf node. In the process of taking optimal paths, we also store suboptimal paths, which could possibly lead to good decisions and show them as recommendations to the farmer too, so that the farmer is free to choose whichever option suits them best.

Figure 11 represents the rule based model that is used to provide the recommendation to the farmers. Herein we use a rule based/decision based smart engine instead. The rule engine will connect two farmers together (one who wants to rent the equipment and the other who owns the equipment). 
TABLE 3: Analysis between farmers' category and whether they availed loan or not with reason and their wish to hire machinery.

Analysis between farmers' category and whether they availed loan or not with reason and their wish to hire machinery

\begin{tabular}{|c|c|c|c|c|}
\hline Farmers' category & Availed loan or not & Reason for loan & Count of reasons & Would you like to hire machinery \\
\hline \multirow{5}{*}{ Small $=377$} & \multirow{4}{*}{ Yes $=179$} & Plantation, fertilization & 10 & 179 \\
\hline & & New machinery & 127 & \\
\hline & & Land development & 42 & \\
\hline & & Education & 0 & \\
\hline & $\mathrm{No}=198$ & Not availed loan & 198 & 197 \\
\hline \multirow{5}{*}{ Medium $=179$} & \multirow{4}{*}{ Yes $=53$} & Plantation, fertilization & 0 & 51 \\
\hline & & New machinery & 28 & \\
\hline & & Land development & 25 & \\
\hline & & Education & 0 & \\
\hline & $\mathrm{No}=126$ & Not availed loan & 126 & 121 \\
\hline \multirow{5}{*}{ Large $=6$} & \multirow{4}{*}{ Yes $=4$} & Plantation, fertilization & 0 & 2 \\
\hline & & New machinery & 4 & \\
\hline & & Land development & 0 & \\
\hline & & Education & 0 & \\
\hline & $\mathrm{No}=2$ & Not availed loan & 2 & 2 \\
\hline
\end{tabular}

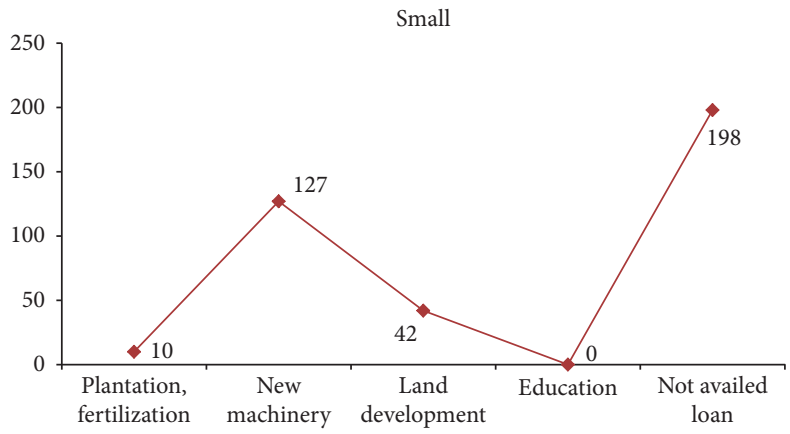

(a)

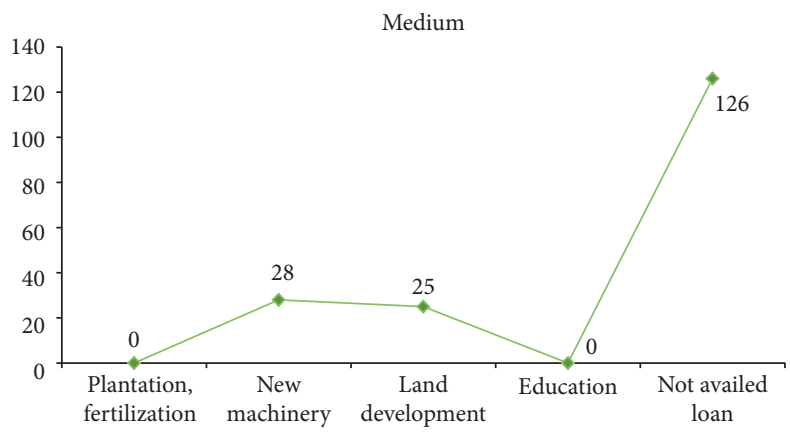

(b)

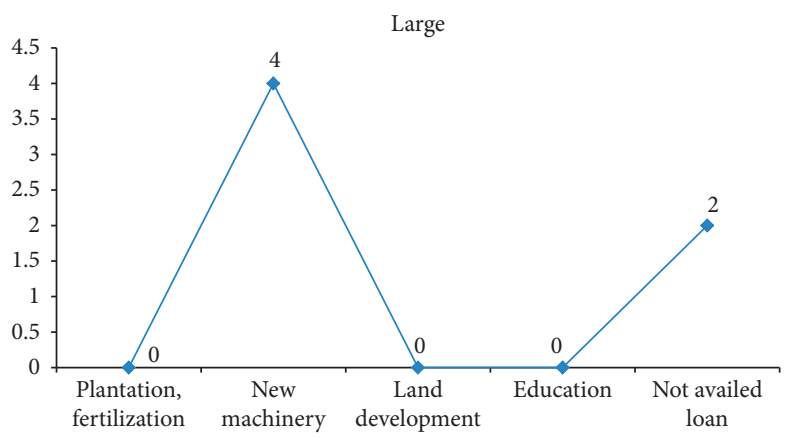

(c)

FiguRE 6: Relationship between farmers category and the reason for loan and wish to hire machinery. 
TABLE 4: Categorywise considerable distance while lending machinery.

\begin{tabular}{|c|c|c|}
\hline Farmers category & Considerable distance while lending machinery (up to) & Count of farmers \\
\hline \multirow{5}{*}{ Small } & No tools & 179 \\
\hline & $3 \mathrm{~km}$ & 10 \\
\hline & $5 \mathrm{~km}$ & 89 \\
\hline & $10 \mathrm{~km}$ & 99 \\
\hline & More than 10 & 0 \\
\hline \multirow{5}{*}{ Medium } & No tools & 0 \\
\hline & $3 \mathrm{~km}$ & 5 \\
\hline & $5 \mathrm{~km}$ & 86 \\
\hline & $10 \mathrm{~km}$ & 86 \\
\hline & More than 10 & 2 \\
\hline \multirow{5}{*}{ Large } & No tools & 0 \\
\hline & $3 \mathrm{~km}$ & 0 \\
\hline & $5 \mathrm{~km}$ & 2 \\
\hline & $10 \mathrm{~km}$ & 4 \\
\hline & More than 10 & 0 \\
\hline
\end{tabular}

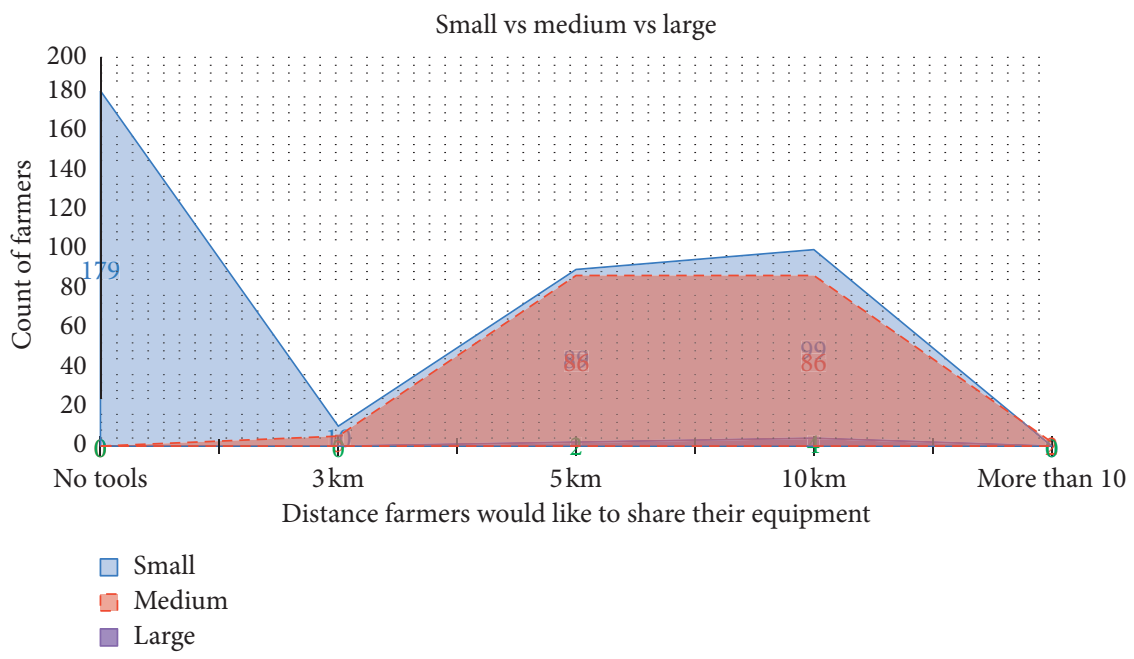

FIGURE 7: Different categories of farmers are comfortable for sharing their tools.

Table 5: Categories of the farmers with different kinds of crops, difficulty in hiring machinery, and their reasons for loan.

Analysis between different categories of farmers and different types of crops they grow versus difficulty in finding machinery and taking loan for it

\begin{tabular}{|c|c|c|c|c|c|}
\hline & $\begin{array}{l}\text { Farmers } \\
\text { category }\end{array}$ & $\begin{array}{l}\text { Wheat, maize, rice, } \\
\text { pulses, sugarcane, } \\
\text { fruits, and vegetables }\end{array}$ & $\begin{array}{l}\text { Crops } \\
\text { Wheat, maize, rice, pulses, sugarcane, } \\
\text { fruits and vegetables, minor crops } \\
\text { (chips ornamental plants, and } \\
\text { raspberries) }\end{array}$ & $\begin{array}{l}\text { Hire machinery } \\
\text { Do you find it difficult } \\
\text { to find machinery in } \\
\text { harvesting time }\end{array}$ & $\begin{array}{l}\text { Loan } \\
\text { Reason for } \\
\text { loan-new } \\
\text { machinery }\end{array}$ \\
\hline \multirow{3}{*}{ Traditional } & Small & 346 & 29 & 375 & 126 \\
\hline & Medium & 155 & 23 & 177 & 28 \\
\hline & Large & 1 & 0 & 1 & 0 \\
\hline $\begin{array}{l}\text { Type of } \\
\text { farming }\end{array}$ & $\begin{array}{l}\text { Farmer } \\
\text { category }\end{array}$ & $\begin{array}{l}\text { Wheat, maize, rice, } \\
\text { pulses, sugarcane, fruits } \\
\text { and vegetables }\end{array}$ & $\begin{array}{l}\text { Wheat, maize, rice, pulses, sugarcane, } \\
\text { fruits and vegetables, minor crops } \\
\text { (chips ornamental plants, and } \\
\text { raspberries) }\end{array}$ & $\begin{array}{l}\text { Do you find it difficult } \\
\text { to find machinery in } \\
\text { harvesting time }\end{array}$ & $\begin{array}{l}\text { Reason for } \\
\text { loan-new } \\
\text { machinery }\end{array}$ \\
\hline \multirow{3}{*}{$\begin{array}{l}\text { Traditional, } \\
\text { modern }\end{array}$} & Small & 1 & 1 & 2 & 1 \\
\hline & Medium & 1 & 0 & 1 & 0 \\
\hline & Large & 4 & 1 & 0 & 4 \\
\hline
\end{tabular}



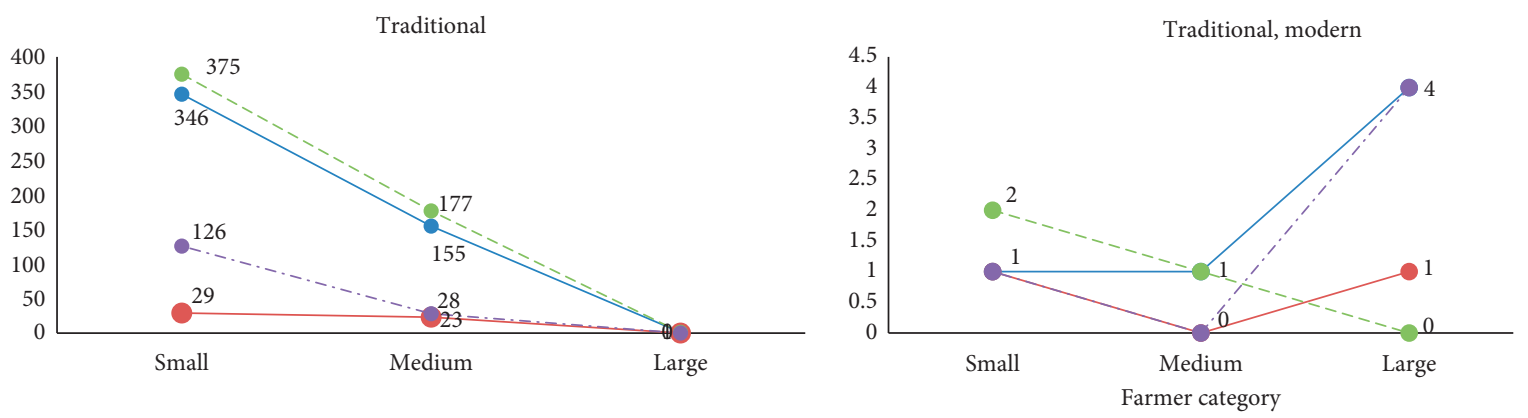

- Wheat, maize, rice, pulses, sugarcane, fruits and vegetables

- Wheat, maize, rice, pulses, sugarcane, fruits and vegetables, minor crops (chips ornamental plants, and raspberries)

- Do you find it difficult to find machinery in harvesting time

$\rightarrow-$ Reason of loan - new machinery

- Wheat, maize, rice, pulses, sugarcane, fruits and vegetables

- Wheat, maize, rice, pulses, sugarcane, fruits and vegetables, minor crops (chips ornamental plants, and raspberries)

- Do you find it difficult to find machinery in harvesting time

$\rightarrow$ - Reason of loan - new machinery

FIGURE 8: Analysis between traditional and modern farming and types of crops they grow versus difficulty in finding machinery and loan.

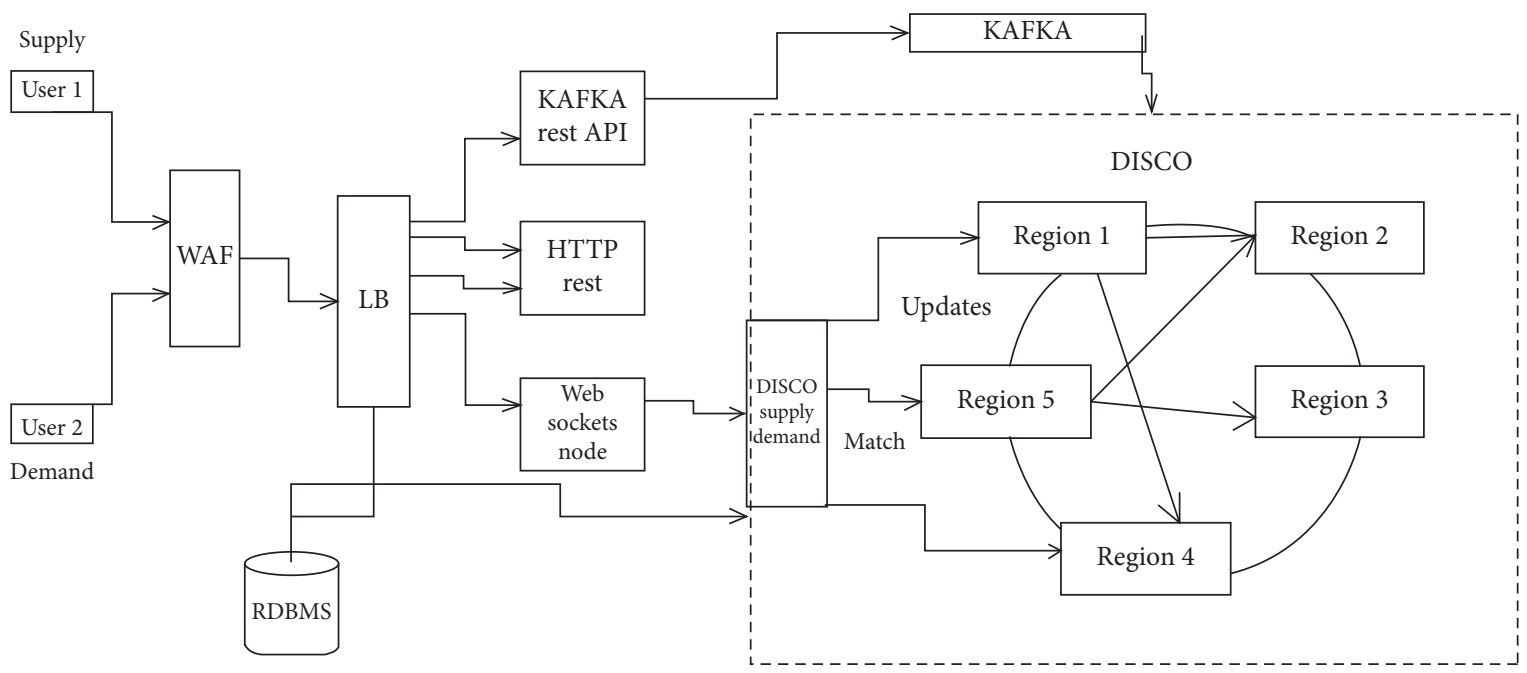

FIGURE 9: Mapping software architecture.

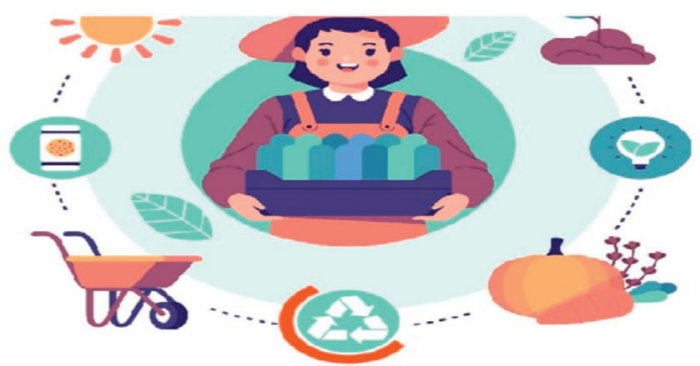

Smart Tillage
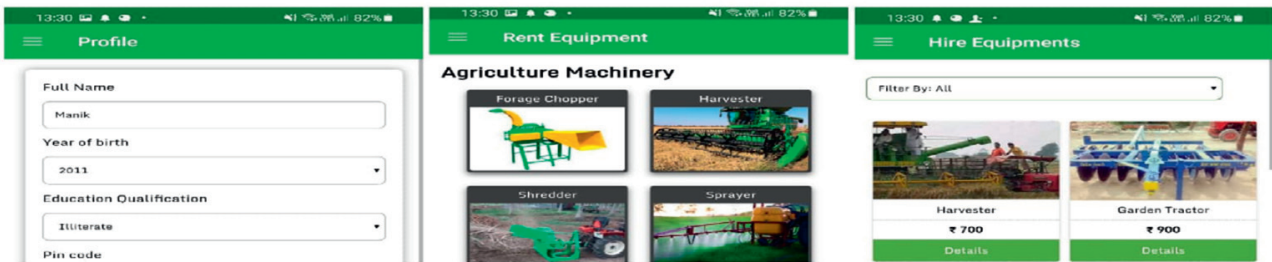

Figure 10: Smart Tillage framework. 


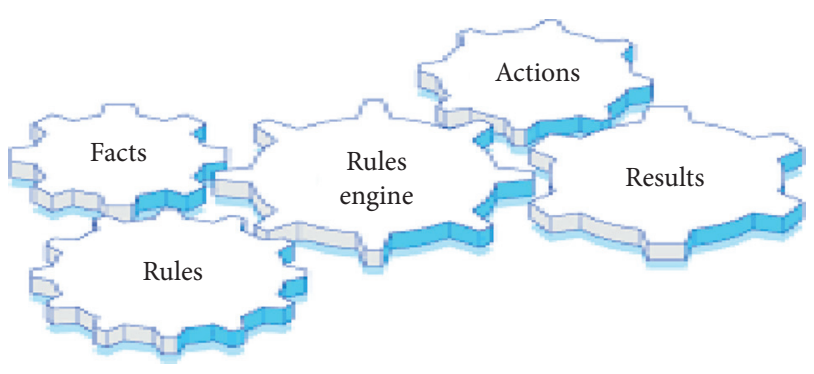

FIGURE 11: Systematic study for the rule-based model.

The connection is based on whatever rule has been placed in the system. For example, maybe a particular farmer is growing maize and his harvest is due in June; he wants to rent a combine. The rule engine can suggest to him a couple of days before it that he has planted maize and its harvest is due soon. The system knows this because the farmer has entered all the details of his crop in the database. The system also suggests to him that the combines can be rented from another farmer or a list of farmers. Further decision rules algorithm will be used to narrow down the search and to get specific results. A set of rules will be used in decision rules algorithm, which will individually fetch the required results. A decision rule is utilized to represent the information involved in a critical class of data frameworks called decision tables, which play a huge part in numerous applications. The essential segments of a choice table T are an arrangement of items indicated as $\mathrm{U}$ and two disjoint sets of features $\mathrm{A}$ and $\mathrm{D}$ called the syntactic (condition) and expert (action or decision) features. In a decision table, the information about these objects is communicated through the assignment of values to the selected conditional and decision traits. Subsequently, a decision table is a sort of solution that determines what actions ought to be embraced when a few conditions are fulfilled.

A challenging issue in rule formation is the evaluation of derived rules in view of the quality. Quality of a decision rule is measured as far as its prescient exactness, thoroughness, and intriguing quality. The majority of the rule mining algorithms form numerous decision rules even for small datasets. An extensive arrangement of rules may give high predictive precision; however, it is not conceivable as it is infeasible for the people to manually investigate them to pick up knowledge into the application area. Thus, as a postprocessing operation to rule mining, productive and viable strategies are required to extract intriguing, significant, and novel rules automatically. Because of this, a new rule evaluation measure is presented in this thesis, in view of which an objective and programmed approach to rank and extract critical rules is proposed.

\section{Conclusions}

To conclude, many of the industries are replacing human labor with automation. There are several farm robots that perform major agricultural tasks, such as irrigation, planting, and harvesting. To increase the agricultural production and productivity, the farm power and machinery with the farm operator is mandatory but this machinery is not easy to reach for every farmer. To view this issue, by setting up various service centers in India, custom hiring services provide better scope for customers. Metaheuristic is one of the promising techniques, which is useful to find the optimized result for renting and sharing equipment. In the context of agriculture, Smart Tillage is basically concerned to upgrade the quality and efficiency of the agriculture. This will further help to improve the lifestyle of farmer by reducing difficult tasks and heavy labor. Our main emphasis is on equipment sharing and renting to build the smart farming. In this research, we have conducted a survey of 562 farmers. We reached the point that most of the farmers lie under the burden of debt because they are unable to buy new machinery. Herein the conducted survey tells us about demand and requirement of renting and sharing equipment. From this gathered survey and viewing the demand of the farmers we have made an information system named Smart Tillage, which can accommodate the farm equipment sharing and renting considering seasonal fluctuations, market demand, and pricing as per the crop cycles which will handle the catastrophic task and also improve the productivity in India. To upgrade the knowledge of the farmers, we have developed and launched an Internet-based mobile application for the various types of end users, which can be used to advertise, reserve, rent, and share agricultural equipment.

\section{Data Availability}

The data are available upon request to the corresponding author.

\section{Conflicts of Interest}

The authors declare that they have no conflicts of interest.

\section{References}

[1] A. Ahmed, "Farm Mechanization in Bangladesh: evidence from IFPRI National Household Survey," in Proceedings of the Rural Mechanization: Policy and Technology Lessons from Bangladesh and Other Asian Countries, pp. 7-8, Dhaka, Bangladesh, March 2013.

[2] P. Soni and Y. Ou, Agricultural Mechanization at a Glance Selected Country Studies in Asia on Agricultural Machinery Development, United Nations Asian and Pacific Centre for Agricultural Engineering and Machinery, Bangkok, Thailand, 2010.

[3] A. Bagheri and A. Ghorbani, "Adoption and non-adoption of sprinkler irrigation technology in Ardabil Province of Iran," African Journal of Agricultural Research, vol. 6, no. 5, pp. 1085-1089, 2011.

[4] S. Biggs, S. Justice, and D. Lewis, "Patterns of rural mechanization, energy and employment in South Asia: reopening the debate," Economic and Political Weekly, vol. 46, no. 9, pp. 78-82, 2011.

[5] S. Biggs and S. Justice, "Rural and agricultural mechanization: a history of the spread of small engines in selected Asian 
countries," in Proceedings of the International Food Policy Research Institute, Washington, DC, USA, 2015.

[6] y. Bigot and H. p. binswanger, Agricultural Mechanization and the Evolution of Fanning Systems in Sub-saharan Africa, Johns Hopkins University Press, Baltimore, MD, USA, 1987.

[7] L. J. Clarke, "Strategies for agricultural mechanization development: the roles of the private sector and the government," Agricultural Engineering International: CIGR Journal, vol. 2, 2000.

[8] L. J. Clarke, Agricultural Engineering Branch, Agricultural Support Systems Division, FAO, Rome, Italy, 1997.

[9] CSAM, 2nd Regional Forum on Sustainable Agricultural Mechanization in Asia and the Pacific, Centre for Sustainable Agricultural Mechanization (CSAM) United Nation Economic and Social Commission for Asia and the Pacific (UNESCAP), Bangkok, Thailand, 2014.

[10] X. Diao, F. Cossar, N. Houssou, S. Kolavalli, K. Jimah, and P. Aboagye, "Mechanization in Ghana searching for sustainable service supply models," in Proceedings of the FPRJ, Houston, TX, USA, 2012.

[11] X. Diao, F. Cossar, N. Houssou, and S. Kolavalli, "Mechanization in Ghana: emerging demand, and the search for alternative supply models," Food Policy, vol. 48, pp. 168-181, 2014.

[12] FAO, Multiform Use of Agricultural Machinery, Food and Agriculture Organization of the United Nations, Rome, Italy, 1985.

[13] G. Feder and R. Slade, "The acquisition of information and the adoption of new technology," American Journal of Agricultural Economics, vol. 66, no. 3, pp. 312-320, 1984.

[14] A. J. J. Folefack, "The determinants for the adoption of compost from household waste for crop production by fanners living nearby Yaounde, Cameroon: descriptive and logit model approaches 15 of analysis," International Journal of Biological and Chemical Sciences, vol. 9, no. 1, pp. 308-328, 2015.

[15] T. Farooq and M. Shabaz, "Revenue generation from recommendation system using sentimental analysis," International Journal of Innovative Technology and Exploring Engineering, vol. 8, no. 6, pp. 351-354, 2019.

[16] B. k. Ghosh, "Determinants of farm mechanisation in modern agriculture: a case study of burdwan districts of West Bengal," International Journal of Agricultural Research, vol. 5, no. 12, pp. 1107-1115, 2010.

[17] G. Giles, The Reorientation of Agricultural Mechanization for the Developing Countries. Part 1-Policies and Attitudes for Action Programmes, Agricultural Services Div. Expert Panel on the Effects of Farm Mechanization on Proclktion and Employment, Rome, Italy, 1975.

[18] D. Gisselquist and G. Jean-Marie, "An argument for deregulating the transfer of agricultural technologies to developing countries," The World Bank Economic Review, vol. 14, no. 1, pp. 111-127, 2000.

[19] H. Hamidah and T. Soedarto, "Analisis operasional traktor tangan pada usaha pelayanan jasa alsintan pola kerjasama operasional di Kab," Gresik. Jurnal Ilmu $\neg$ Ilmu Ekonomi, vol. 6, no. 2, pp. 76-85, 2006.

[20] K. Houmy, L. Clarke, E. Ashbumer, and J. Kienzle, Agricultural Mechanization in Sub-saharan Africa: Guidelines for Preparing a Strategy, Food and Agriculture Organization of the United Nations, Rome, Italy, 2013.

[21] N. Houssou, K. Diao, F. Cossar, S. Kolavalli, K. Jimah, and P. Aboagye, "Agricultural mechanization in Ghana: is specialization in agricultural mechanization a viable business model?" in Proceedings of the FPRI, Philadelphia, PA, USA, 2013.

[22] S. S. Hussain, D. Byerlee, and P. W. Heisey, "Impacts of the training and visit extension system on farmers' knowledge and adoption of technology: evidence from Pakistan," Agricultural Economics, vol. 10, no. 1, pp. 39-47, 1994.

[23] L. Hutahaean, R. H. Anasiru, and I. Sarasutha, "Kelayakan usaha pelayanan jasa alsintan di Sulawesi tengah," Jurnal Pengkajian Clan Pengembangan Reknologi Pertcmian, vol. 8, no. 1, pp. 150-163, 2005.

[24] IRRL, "Small farm equipment for developing countries," in Proceedings of the International Conference on Small Farm Equipment for Developing Counties: Past Experiences and Future Priorities, Manila, Asia, 1986.

[25] A. Julius, "Factors limiting small-scale farmers' access and use of tractors for agricultural mechanization in Abuja, north central zone, Nigeria," European Journal of Sustainable Development, vol. 3, no. 1, pp. 115-124, 2014.

[26] R. N. Kaul, Introduction to Agricultural Mechanization, Macmillan, London, UK, 1985.

[27] P. Kic and R. Zewdie, "Assistance in promotion of agricultural mechanization in developing countries," Ama-agricultural Mechanization in Asia Africa and Latin America, vol. 44, no. 4, pp. 31-33, 2013.

[28] J. Kienzle, J. E. Ashbumer, and B. Sims, Mechanization for Rural Development: A Review of Patterns and Progress from Around the World, Food and Agriculture Organization of the United Nations, Rome, Italy, 2013.

[29] M. Rakhra and R. Singh, "A study of machinery and equipment used by farmers to develop an uberized model for renting and sharing," Materials Today Proceedings, 2020.

[30] H. Takeshima, H. Edeh, T. A. Lawal, and M. Thiaka, "Tractor owner-operators in Nigeria: insights from a small survey in Kaduna and Nasarawa states," in Proceedings of the IFPRI, Washington, DC, USA, 2014.

[31] M. Rakhra and R. Singh, "Internet based resource sharing platform development for agriculture machinery and tools in Punjab," in Proceedings of the 2020 8th International Conference on Reliability, Infocom Technologies and Optimization (Trends and Future Directions) (ICRITO), pp. 978-981, Noida, India, June 2020.

[32] H. Takeshima, "Drivers of growth in agricultural returns to scale: the hiring in of tractor services in the Terai of Nepal," in Proceedings of the IFPRI, Viterbo, Italy, May 2015.

[33] B. Sims and J. Kienzle, "Making mechanization accessible to smallholder farmers in sub-Saharan Africa," Environments, vol. 3, no. 2, p. 18, 2016.

[34] U. Paman, S. Inaba, and S. Uchida, "Economic aspects of machinery hire services managed by farmer groups in Kampar regency, Indonesia," Applied Engineering in Agriculture, vol. 32, no. 2, pp. 169-179, 2016.

[35] T. E. Simalenga, Agricultural Mechanization in Southern African Countries, Food and Agriculture Organization of the United Nations, Rome, Italy, 2013.

[36] B. Lin and H. Deng, "An empirical analysis of the agricultural labor force aging on the impact of land use efficiency-based in Zhejiang province rural fixed observation point data," Chinese Rural Economy, vol. 4, pp. 15-25, 2012.

[37] J. Tang and C. MacLeod, "Labour force ageing and productivity performance in Canada," Canadian Journal of Economics/Revue Canadienne D', vol. 39, no. 2, pp. 582-603, 2006.

[38] M. Li and L. Zhao, "Agricultural labor "aging” phenomenon and its impact on agricultural production-based on 
empirical analysis of Liaoning province," Issues in Agricultural Economy, vol. 10, pp. 12-18, 2009.

[39] B. Siliverstovs, K. A. Kholodilin, and U. Thiessen, "Does aging influence structural change? Evidence from panel data," Economic Systems, vol. 35, no. 2, pp. 244-260, 2011.

[40] J. Yang, G. Yang, and X. Hu, "Age effects on the agricultural labor force farmers cultivated land use efficiency-evidence from different levels of economic development in the region," Resources Science, vol. 9, pp. 1691-1698, 2011. 